\title{
EXPRESSÃO E REGULAÇÃO EMOCIONAL
}

\section{NO CONTEXTO DE TRABALHO: UM ESTUDO COM SERVIDORES PÚBLICOS}

\begin{abstract}
ANA PAULA GRILLO RODRIGUES
Doutora em Administração pelo Departamento de Administração da Universidade Federal da Bahia (Ufba).

Professora do Departamento de Administração Pública da Universidade do Estado de Santa Catarina (Udesc). Avenida Madre Benvenuta, 2.037, Itacurubi, Florianópolis - SC - Brasil - CEP 88035-001

E-mail: apgrodrigues@uol.com.br

\section{SÔNIA GUEDES GONDIM}

Doutora em Psicologia pelo Instituto de Psicologia da Universidade Federal do Rio de Janeiro (UFRJ). Professora do Departamento de Psicologia da Universidade Federal da Bahia (Ufba). Rua Aristides Novais, s/n, Federação, Salvador - BA - Brasil - CEP 40210-630 E-mail:sggondim@gmail.com
\end{abstract}




\section{RESUMO}

As emoções caracterizam-se por um conjunto de respostas integradas que envolvem alterações fisiológicas e motoras (que preparam o indivíduo para agir) e sentimentos associados a experiências internas (que propiciam uma avaliação da situação). As expressões emocionais são cruciais para o desenvolvimento e regulação das relações interpessoais. Saber lidar com as emoções pessoais e com as dos demais tem se tornado um importante requisito nas relações do indivíduo com a organização. O manejo das emoções repercute nas interações com colegas de trabalho e no atendimento a clientes. Situações do cotidiano de trabalho, mudanças organizacionais e características de clientes e colegas de trabalho envolvem emoções que necessitam ser reguladas. A regulação emocional pode ser definida como uma tentativa controlada ou automática de lidar com as emoções, indicando quando e a forma como elas serão sentidas e expressas. O setor público vem passando nos últimos anos por mudanças na sua estrutura e dinâmica que exigem manejo emocional da parte dos servidores públicos, demandando estudos empíricos que permitam compreender melhor essa realidade. $\mathrm{O}$ estudo quantitativo apresentado neste artigo analisou a relação entre emoções, estratégias de regulação emocional e variáveis sociodemográficas de servidores públicos que trabalham em organizações do Sul do país. Para a coleta de dados, foi utilizado um questionário com exemplos de situações hipotéticas do cotidiano do trabalho para que os participantes escolhessem expressões emocionais a elas associadas e as estratégias de regulação emocional que poderiam ser usadas em tais situações. A amostra contou com 400 trabalhadores de instituições públicas. Os resultados indicaram que, nas situações cotidianas negativas, as emoções que prevaleceram estavam associadas à raiva, e as que menos apareceram estavam associadas ao medo. As estratégias de regulação emocional usadas para lidar com as situações foram as de ação profunda. Os resultados apresentaram também diferenças na regulação emocional quanto ao gênero, nível de atuação na instituição pública e regime de trabalho. 


\section{PALAVRAS-CHAVE}

Emoções. Estratégias de regulação emocional. Serviço público. Psicologia organizacional. Comportamento organizacional.

\section{INTRODUÇÃO}

As emoções são fundamentais para o ser humano e estão presentes em toda a sua vida. São elas que aproximam, criando laços, afastando e sinalizando situações de risco, trazem alegria, causam tristeza, despertam sinais de alerta ou permitem momentos de relaxamento. As expressões emocionais são cruciais para o desenvolvimento e regulação das relações interpessoais (Ekman, 2000).

A forma como cada um responde emocionalmente ao ambiente ajuda a definir a qualidade da sua interação com o meio. O indivíduo, de modo automático ou controlado, consciente ou até mesmo inconsciente irá definir a forma como utilizará e regulará suas emoções.

A regulação emocional pode ser definida como uma tentativa controlada ou automática de lidar com as emoções, indicando quando e a maneira como elas serão sentidas e expressas (Gross, 20I3). O processo de regulação emocional consiste, portanto, em manejar emoções para que o indivíduo se adapte melhor ao contexto em que se encontra, sendo capaz de modular a emoção quanto ao tempo de duração, magnitude e latência. Suas funções são defender o indivíduo de situações indesejáveis, evitar sofrimentos ou manter situações agradáveis, com o intuito de preservar o seu bem-estar.

O interesse em investigar o uso de estratégias de regulação emocional em servidores públicos deve-se às mudanças que ocorreram na forma de trabalhar. Se antes prevalecia a conformidade a processos burocráticos e rotineiros, bastando conhecer as regras e as leis para cumprir as tarefas, atualmente as demandas se modificaram. A perspectiva burocrática tem dado espaço para uma abordagem mais gerencialista. Tal abordagem, também conhecida como "nova administração pública", credita ao Estado não apenas instrumentos que garantam sua propriedade e seus contratos, mas também que este formule e implemente políticas públicas estratégicas para sociedade. A estrutura e o contexto do serviço público estão mudando. Neste momento de transição, surgem diferentes valores, crenças, modelos de política, entre outros elementos que interferem no convívio social. Essas mudanças provocam inseguranças que são manifestadas emocionalmente e controladas a partir das estratégias de regulação emocional. Por isso, a necessidade de entender melhor como se manifestam as emoções no contexto das organizações públicas. 
O estudo teve como objetivo analisar relações entre emoções, estratégias de regulação emocional e variáveis sociodemográficas de servidores públicos. O artigo está estruturado em cinco seções incluindo esta introdução. Na seção seguinte, serão apontados os conceitos teóricos usados no estudo, nos quais se abordam recortes da literatura sobre emoções, regulação emocional e emoções no trabalho. Subsequentemente, apresentar-se-ão o método, os resultados e as discussões, as conclusões e menções às limitações do estudo.

\section{EMOÇÕES: UM CONCEITO COMPLEXO}

Apesar de os psicólogos e neurologistas concordarem que as emoções influenciam no pensamento, na tomada de decisão, nas relações sociais, no bem-estar, na saúde física e mental dos indivíduos, não há consenso sobre a definição da "emoção. Em recente estudo realizado por Izard (20IO), a emoção tem apresentado múltiplos sentidos na literatura, demonstrando uma estrutura complexa e desafiadora para os pesquisadores comportamentais.

De acordo com Mayer, Roberts e Barsade (2006), as emoções caracterizam-se por um conjunto de respostas integradas que envolvem alterações fisiológicas e motoras (que preparam o indivíduo para agir) e sentimentos associados a experiências internas (que propiciam uma avaliação da situação). Gazzaniga e Heatherton (2005) complementam afirmando que as emoções são respostas imediatas a eventos ambientais e envolvem avaliação subjetiva, processos psicológicos e crenças cognitivas. Agüera (2008) define a emoção como um impulso para ação desencadeado por variáveis fisiológicas que podem ser mensuráveis e observáveis, tais como ritmo de batimentos cardíacos, respiração, tensão arterial, sudorese e dilatação das pupilas.

Para Reeve (2006), os processos psicológicos que desencadeiam as emoções fazem parte de um construto que coordena quatro experiências psicológicas em um padrão sincronizado. Essas quatro experiências são: sentimentos, excitação corporal, estado propositivo e expressão social. O componente sentimento aparece como um elemento que fornece subjetividade ao fenômeno emocional. O sentimento vai depender da intensidade e da qualidade com que a emoção é percebida. A excitação corporal inclui uma ativação biológica e fisiológica que prepara o corpo para uma determinada ação, na qual podem ser percebidas mudanças na frequência cardíaca, postura, musculatura do corpo e da face. O estado propositivo refere-se à busca de metas, ao supor que cada emoção tem um propósito e uma direção. A expressão social está intimamente relacionada ao aspecto comunicativo da emoção. Por meio dos gestos, das expressões e do tom de voz, as emoções se tornam públicas enquanto são expressas. 
Os especialistas distinguem as emoções básicas das secundárias. Perspectivas biológicas (Ekman, I994, 2000; Plutchik, I980; Tomkins, I984) e cognitivistas (Lazarus, I982) vinculam as emoções básicas ao processo evolutivo, destacando o seu valor adaptativo para desempenhar tarefas fundamentais para vida. As emoções secundárias seriam constituídas por meio de processos de aprendizagem, possuindo um grau mais variado de significados e sentidos em virtude das diferenças individuais e culturais (Damasio, I996).

Darwin (2009) considera a expressão das emoções básicas como poderosa forma de comunicação não verbal, sendo identificada em qualquer pessoa e qualquer cultura, em virtude de as manifestações físicas e faciais de cada uma delas serem muito semelhantes. As emoções básicas propostas por Darwin (2009) estão presentes em muitas teorias contemporâneas das emoções (Ekman, I992; Izard, I99I; Sherer, 2000; Weiner, I986). De acordo com Ekman (I992, I994), as emoções básicas são inatas e expressas de maneira distinta e seriam em número de seis: medo, raiva, nojo, tristeza, alegria e surpresa.

Izard e Ackerman (2000), Berkowitz (2000), Reeve (2006) e Esperidião-Antônio et al. (2008) destacam as principais funções de cada uma das emoções básicas. O sorriso, frequentemente presente na alegria, é conhecido universalmente como um estado de receptividade para a interação humana. Para Izard e Ackerman (2000), nenhuma outra emoção apresenta tantos benefícios para o fortalecimento e suporte do vínculo social, com tão baixo custo, quanto a alegria.

A tristeza também fortalece o vínculo social, porém de modo diferente. Nesse caso, ele se dá por meio da aproximação de pessoas oferecendo ajuda àquelas que, de alguma forma, necessitam de apoio. Essa emoção é responsável pela desaceleração dos processos cognitivos e motores, fazendo com que o indivíduo tenha maior autocontrole, reflita sobre a situação e aumente o leque de possibilidades de adaptação (Reeve, 2006).

O medo é ativado pelo aumento da intensidade de uma estimulação neural proveniente de uma situação perigosa. Sua principal função é alertar o indivíduo para situações de perigo, estimulando a fuga ou o enfrentamento. Esse alerta pode ser tanto psicológico quanto físico. O medo faz com que a pessoa fique mais atenta e prepare seu organismo para agir da forma mais adaptativa. A raiva aparece como resultado de limitações físicas e psicológicas, e é desencadeada a partir de uma interpretação subjetiva do indivíduo, algumas vezes ativada por processos automáticos (Berkowitz, 2000). Essa emoção mobiliza e sustenta energias em alto nível, deixando a pessoa com mais força e o corpo em alerta para ação. Em muitos casos, a raiva está intimamente relacionada aos comportamentos agressivos (Esperidião-Antônio et al., 2008), embora, em algumas situações, a reação possa ser passiva como a de mágoa (Reeve, 2006). A raiva ou ira é considerada a emoção mais passional, sendo responsável tanto por comportamentos impulsivos 
como de mudança social. Na história, muitos movimentos sociais, políticos, culturais e religiosos foram movidos, principalmente, pela ira.

A surpresa é caracterizada pela ocorrência súbita e inesperada de um estímulo que a ativa de forma breve e pode ser agradável ou desagradável. Depois do elemento-surpresa, a emoção pode se transformar em outras emoções que causam prazer ou desprazer, como alegria ou medo (Freitas-Magalhães, 20IO). A surpresa, assim como o interesse, cria o desejo de explorar, investir ou buscar informações sobre o estímulo causador da emoção (Reeve, 2006). Enfim, o nojo é uma emoção negativa, e a expressão dele sugere uma aversão em um nível físico ou psicológico, com o intuito de o indivíduo se defender ante um estímulo indesejado que possa ferir a integridade dele (Darwin, 2009).

Além do reconhecido papel adaptativo das emoções básicas, há que se destacar a função social das emoções. O conhecimento da função das emoções possibilita compreender que cada uma delas visa motivar, organizar e manter um conjunto de comportamentos que contribuem para o desenvolvimento da personalidade do indivíduo. A emoção exerce um importante papel no processo motivacional. A organização diz respeito à função das emoções na percepção, aumentando a seletividade da atenção e ajudando a determinar o conteúdo da memória, a fim de favorecer a adaptação do indivíduo, auxiliando no desenvolvimento de sua personalidade (Izard \& Ackerman, 2000).

As emoções fazem parte de processos sociocognitivos, pois são aprendidas e desenvolvidas para facilitar a inserção do indivíduo na sociedade. Apesar de as emoções serem compreendidas também como experiências individuais e subjetivas, elas são parte de um fenômeno oriundo da vida social. São mediadoras das relações interpessoais, fazendo com que os indivíduos se aproximem ou se afastem de seus pares ou de situações, conforme seus interesses e valores culturalmente compartilhados (Gondim \& Borges-Andrade, 2009). Na construção das relações sociais, o modo como o indivíduo expressa suas emoções repercute na resposta do outro e terá influência no tipo e na qualidade da interação.

Para manter as relações sociais e preservar o seu bem-estar, o indivíduo precisa gerenciar bem as emoções. Esse processo de perceber o estímulo, avaliar a situação e o contexto e também modular a resposta emocional é chamado de regulação emocional (Gross, I998). O estudo da regulação emocional é importante para que o indivíduo compreenda os caminhos que o levam a agir de determinada maneira.

\subsection{REGULAÇÃO EMOCIONAL}

A regulação emocional cumpre um papel importante no processo de ajustamento social, pois é, por meio dela, que se assegura a qualidade das relações 
sociais, familiares, de amizade e trabalho. A forma como um indivíduo se manifesta vai interferir no comportamento e nas emoções daqueles que com ele se relacionam, criando, assim, laços sociais mais duradouros. Existem muitos componentes emocionais que influenciam no processo de regulação emocional, fazendo com que a regulação seja mais ou menos efetiva para preservar o bem-estar psicológico.

Para Gross e Thompson (2006), há características marcantes no processo de regulação emocional. Uma delas se refere à tendência de regular mais as emoções negativas do que as positivas. Isso pode ser explicado, em parte, porque nossos ancestrais faziam pouco uso da linguagem verbal, necessitando de expressões faciais emocionais para afugentar os inimigos (raiva), fugir deles, caso fossem mais fortes (medo); evitar alimentos que pudessem causar danos à saúde (asco); e mostrar para os demais que a interação era ruim (tristeza), o que exigia reparação para nova aproximação. Outra característica apontada pelos mesmos autores está relacionada à suposição de que a regulação emocional, frequentemente, ocorre para aliviar tensões. Uma terceira característica diz respeito ao nível de consciência do processo de regulação emocional. A repetição da experiência afetiva faz desencadear automaticamente a regulação, inicialmente consciente. Ou seja, a regulação automática está relacionada à ausência de consciência, intenção e controle, pois esse tipo de regulação ocorre sem que o indivíduo perceba seu processo. No entanto, a regulação pode ser intencional e controlada, com alto nível de consciência do processo.

Sobre o momento de ativação da regulação emocional, ele pode ser focado em aspectos antecedentes e consequentes (Gross, I998, I999). A ativação antecedente ocorre antes de a emoção ser eliciada, como forma antecipada de enfrentar a situação em vista. A ativação consequente está relacionada ao controle da emoção depois de ativada, a fim de atenuar suas consequências. Como a estratégia de regulação emocional antecedente exige uma preparação consciente do indivíduo para enfrentar a emoção, é possível afirmar que o processo seja acompanhado de uma mudança de atitude, de modo que haja uma nova reação do indivíduo diante do acontecimento e, em consequência, da experiência e expressão emocional. Por seu objetivo de intencionalmente provocar uma mudança de sentimento, a forma antecedente de regular a emoção é também chamada de regulação emocional profunda, sendo as estratégias pertencentes a esse grupo consideradas mais eficazes para preservação do bem-estar (Augustine \& Hemenover, 2008; Gross \& John, 2003; Quoidbach, Berry, Hansenne, $\&$ Mikolajczak, 20I0). Por sua vez, a ativação consequente, também denominada de estratégia superficial, está relacionada ao controle da emoção após ter sido ativada, como forma de minimizar seus efeitos negativos, com foco na supressão das expressões emocionais, o que será detalhado adiante. 
A regulação emocional focada nos antecedentes ou de ação profunda pode ocorrer por meio da seleção e modificação da situação, atenção posicionada e mudança cognitiva. A seleção da situação é uma estratégia comportamental e, como o próprio nome sugere, consiste em escolher situações diante de um cenário com inúmeras alternativas, com o intuito de evitar emoções indesejáveis ou favorecer a emergência de emoções desejáveis. Para que esse processo ocorra, é necessário o autoconhecimento para perceber que emoções as situações evocam, de modo que o indivíduo possa decidir por uma delas (Gross \& Thompson, 2006).

Uma situação que potencialmente provoca emoção exige esforços ativos para modificar a situação, de forma a alterar o seu impacto emocional inicial. Essa mudança de curso é denominada modificação da situação e consiste na expressão intencional de uma emoção, com o objetivo de mudar o curso da interação em andamento.

Outra estratégia de regulação emocional profunda é a atenção posicionada que se caracteriza por ser uma estratégia para a mudança do foco de atenção na emoção, que pode ocorrer sob a forma de distração, ruminação e concentração. A distração foca a atenção em aspectos não emocionais da situação ou retira completamente a atenção da situação imediata. Ela faz com que o indivíduo dirija seu pensamento para outros eventos prazerosos. A concentração leva o indivíduo a focalizar a atenção no problema para melhor elaborá-lo. Isso exige a mobilização de recursos cognitivos, deixando os demais aspectos em segundo plano. Essa estratégia de regulação emocional, de acordo com Gross (2007), pode ser considerada uma forma internalizada de selecionar a situação. A ruminação também dirige a atenção, porém ela é direcionada aos sentimentos e às consequências deles. A ruminação faz o indivíduo focar demasiadamente a atenção no evento eliciador da emoção negativa e nas consequências negativas, com o objetivo de esgotar as possibilidades que o fazem sofrer pelo evento.

A mudança cognitiva, como outro meio de regular a emoção de maneira antecedente, refere-se à tentativa de alterar o significado da emoção, seja mudando a forma como se pensa sobre a situação ou sobre a sua capacidade de gerenciar as demandas provenientes dela. Essa estratégia pode ocorrer por meio da negação, reinterpretação ou reavaliação do acontecimento. Entretanto, uma forma de mudança cognitiva que tem recebido atenção especial dos estudiosos da área é a reavaliação, que envolve uma mudança significativa de uma situação, de modo a alterar o impacto emocional e gerar maior congruência entre o que o indivíduo sente e o que expressa (Gross, 2013).

A regulação focada nos aspectos consequentes, estratégia de regulação superficial, ocorre após o indivíduo já ter sido surpreendido pela emoção, tendo que modulá-la, mudando estados fisiológicos pessoais e expressões da emoção. As estratégias superficiais podem ser de quatro tipos: reações fisiológicas, supressão, 
intensificação ou compartilhamento social. A regulação emocional pode ser feita pelo controle de reações fisiológicas do corpo, sendo comum que o indivíduo utilize exercícios respiratórios e de relaxamento ou até mesmo busque a compensação com o uso de drogas lícitas ou ilícitas, para aliviar tensões emocionais. A regulação emocional superficial feita pela supressão consiste na tentativa de suprimir e não deixar transparecer a emoção sentida. A estratégia de intensificação consiste em ressaltar a emoção, a fim de modular a experiência emocional pessoal e o comportamento da outra pessoa. Por exemplo, quando se faz questão de que o outro perceba o desagrado e desconforto da situação, para que este outro se dê conta do problema causado. O compartilhamento social consiste em dividir a experiência emocional com terceiros. Isso pode ocorrer por meio do uso da escrita em diários, conversas com amigos, conhecidos ou até mesmo desconhecidos, na tentativa de atenuar ou modificar seus sentimentos.

\subsection{EMOÇÕES NO TRABALHO}

Quando se considera que a regulação emocional é fundamental para a adaptação do indivíduo ao meio onde está inserido, já que ele atualmente passa, em média, um terço do dia no trabalho, o desenvolvimento dos estudos de estratégias emocionais no ambiente de trabalho é de grande relevância. Miller, Considine e Gardner (2007) destacam cinco tipos de emoções no contexto de trabalho: as emoções demandadas pelas organizações, emoções demandadas pela ocupação do cargo, emoções com o trabalho, emoções no trabalho e emoções em relação ao trabalho. As emoções demandadas pela organização se referem a manifestações emocionais canalizadas para o cumprimento de normas e regras estabelecidas pela organização. Clientes têm demandando, cada vez mais, melhor atendimento por parte dos trabalhadores, o que contribui para o aumento da cobrança de comportamentos mais condizentes com tais demandas. Nem sempre o trabalhador está emocionalmente disposto a atender bem seus clientes, o que pode levar à dissonância emocional, fazendo com que ele utilize estratégias de regulação superficiais ou profundas.

A estratégia de regulação emocional superficial está relacionada à manifestação de emoções que o indivíduo, efetivamente, não está sentindo, como se colocasse uma máscara, a fim de esconder suas reais emoções. A estratégia de regulação profunda, por sua vez, envolve uma mudança interior que leva à expressão emocional condizente com o contexto organizacional. As emoções demandadas pela organização nem sempre podem ser consideradas autênticas, pois, muitas vezes, há incongruência entre as emoções sentidas pelos trabalhadores e aquelas que a organização acredita que sejam importantes de serem exibidas para atingir suas metas. 
As emoções demandadas pela ocupação se referem às expressões emocionais compatíveis com a natureza da profissão ou do cargo que o indivíduo ocupa. Nesse caso, existe uma tendência maior de o indivíduo manifestar emoções positivas, se comparadas com as demandadas pela organização, ou seja, o processo de identificação permite que as emoções sejam manifestações mais autênticas (Diefendorff, Croyle, \& Gosserand, 2005). De acordo com Miller et al. (2007), enfermeiras, terapeutas, assistentes sociais, conselheiros e professores podem ser analisados sob essa perspectiva, pois a qualidade das relações interpessoais é central nessas ocupações. As demandas emocionais desempenham um papel relevante nas relações com seus clientes.

As emoções com o trabalho estão relacionadas àquelas que emergem nas relações com os colegas de trabalho. Por compartilharem muitas experiências e, consequentemente, muitas emoções, as relações de trabalho tendem a gerar intimidade entre os colegas. Essas, de acordo com os autores Miller et al. (2007), talvez sejam as relações que provoquem emoções mais significativas, principalmente por existir a identificação dos colegas, expressa por meio do suporte emocional.

As emoções no trabalho são referentes às emoções que surgem fora do ambiente de trabalho, mas repercutem no contexto de trabalho, como problemas familiares, luto pela perda de alguém querido, entre outras situações. Por fim, as emoções em relação ao trabalho são aquelas que têm como foco o próprio trabalho e estão relacionadas à satisfação.

Diante do estudo das estratégias de regulação emocional, os esforços se dirigem no sentido de compreender como tais fenômenos ocorrem no ambiente laboral, a fim de auxiliar os indivíduos a se ajustar melhor às demandas do mundo do trabalho atual, preservando o seu bem-estar.

\section{MÉTODO}

Este estudo pode ser caracterizado como de natureza quantitativa e de corte transversal, pois utilizou análises descritivas de frequência e análise de variância.

\subsection{PARTICIPANTES}

A pesquisa foi feita em nove organizações públicas das esferas municipal, estadual e federal, totalizando 400 casos: Companhia de Melhoramentos da Capital, Prefeitura Municipal de Florianópolis, Conselho Regional de Corretores de Imóveis, Universidade do Estado de Santa Catarina, Secretaria Estadual da Educação, Tribunal Regional do Trabalho I2 ${ }^{a}$ Região, Secretaria do Patrimônio da União, Polícia Federal e Ministério Público da União. 
A Prefeitura Municipal de Florianópolis (PMF) contou com 22,3\% ( $\mathrm{n}=89$ ) participantes, a Universidade do Estado de Santa Catarina (Udesc) com 6\% (n = 24), o Conselho Regional dos Corretores de Imóveis de Santa Catarina (Creci) com 6,3\% ( $n=25)$, a Secretaria do Patrimônio da União de Santa Catarina (SPU-SC) com 5\% $(\mathrm{n}=20)$, a Secretaria da Educação do Estado de Santa Catarina (SED-SC) com I2,5\% ( $\mathrm{n}=50$ ), o Ministério Público da União em Santa Catarina (MPU) com 3,3\% ( $\mathrm{n}=\mathrm{I3})$, a Polícia Federal de Santa Catarina com I4,5\% ( $\mathrm{n}=58)$, o Tribunal do Trabalho e Tribunal de Justiça de Santa Catarina (TRT-SC) com 4,3\% $(\mathrm{n}=\mathrm{I7}$ ) e a Companhia Melhoramentos da Capital (Comcap) com 26\% ( $\mathrm{n}=104)$.

Quanto ao nível de poder, foram i9,3\% $(\mathrm{n}=77)$ da esfera federal, $24,3 \%(\mathrm{n}=97)$ da estadual e $26,3 \%(n=225)$ da municipal.

Os participantes foram classificados por sexo, estado civil, nível educacional, local de trabalho, área, nível de atuação, regime de trabalho e responsabilidade financeira. Dos 399 que identificaram o sexo, 47,8\% (n = I9I) eram homens e $52 \%(\mathrm{n}=208)$ mulheres.

No que tange ao estado civil, $28 \%(\mathrm{n}=\mathrm{II} 2)$ eram solteiros, $48,3 \%(\mathrm{n}=\mathrm{I9})$ casados, $\mathrm{I} \%(\mathrm{n}=4)$ viúvos, $8,8 \%(\mathrm{n}=35)$ separados ou divorciados e $\mathrm{I} 2,5 \%(\mathrm{n}=50)$ de pessoas que vivem juntas em uma relação consensual não oficializada. Dos 400 participantes, $60 \%(n=240)$ têm filhos.

Quanto ao nível educacional, $0,5 \%(\mathrm{n}=2)$ não ultrapassou o nível de alfabetização, $7 \%(\mathrm{n}=3 \mathrm{I})$ cursaram alguns anos do ensino fundamental, $5 \%(\mathrm{n}=20)$ possuíam ensino médio incompleto, $20,8 \%(\mathrm{n}=83)$ ensino médio completo, I9,5\% (n = 78) nível superior incompleto, 23,5\% ( $\mathrm{n}=94)$ nível superior completo e $22,5 \%(n=90)$ eram pós-graduados. Do total, $15 \%(n=60)$ continuam estudando.

No que se refere à área, esta foi subdividida em área-fim e área-meio. Do total da amostra, 42,3\% ( $\mathrm{n}=\mathrm{I} 69)$ estavam na área-fim e 57,3\% ( $\mathrm{n}=229)$ na área-meio. O nível de atuação foi subdividido em estratégico, tático e operacional. No nível estratégico, estavam 8,5\% ( $\mathrm{n}=34)$, no tático $49 \%(\mathrm{n}=196)$ e no operacional $42,3 \%(n=169)$.

Quanto ao regime de trabalho, 46\% ( $\mathrm{n}=\mathrm{I} 84$ ) eram de estatutários, 30,5\% $(\mathrm{n}=\mathrm{I22})$ de celetistas, 4,8\% ( $\mathrm{n}=\mathrm{I} 9)$ possuíam cargos comissionados, Io,8\% ( $\mathrm{n}=$ 43) de terceirizados e $4,3 \%(n=I 7)$ de estagiários. Cabe ressaltar que, desses, $7 \%(\mathrm{n}=28)$ possuíam outro emprego.

Por último, quanto à responsabilidade financeira, 25,3\% (n= Io) eram os únicos responsáveis financeiramente pelo sustendo da família, 2I,3\% (n = 85) eram os principais responsáveis, $32,8 \%(\mathrm{n}=\mathrm{I3}$ I) dividiam igualmente a responsabilidade financeira da família, $\mathrm{I} 4,3 \%(\mathrm{n}=57)$ contribuíam apenas com uma parte do sustento financeiro da família, e 6,3\% $(\mathrm{n}=25)$ não tinham nenhuma responsabilidade financeira. 


\subsection{INSTRUMENTO}

O instrumento continha I4 situações hipotéticas do cotidiano de trabalhadores no contexto organizacional que foram divididas em dois grupos: sete positivas e sete negativas. O respondente lia a situação hipotética descrita e, na coluna ao lado, selecionava uma emoção que poderia sentir diante de tal situação.

A título de ilustração, será mencionada uma situação de cada tipo.

- Situação positiva: "Imagine que sua organização tenha crescido significativamente nos últimos anos, duplicando seu faturamento anual, e, devido a isso, decidiu oferecer benefícios adicionais a seus trabalhadores".

- Situação negativa: "Imagine que, nas reuniões do seu setor, raramente as ideias, suas ou dos seus colegas, são acatadas pela chefia".

Para cada situação, foram apresentadas faces (gravuras) organizadas em seis grupos que ilustravam as emoções básicas e seus derivativos (Figura I): tristeza (desanimado, triste e deprimido), alegria (satisfeito, empolgado e eufórico), raiva (incomodado, bravo e furioso), surpresa agradável (sensibilizado, surpreendido e deslumbrado), surpresa desagradável (decepcionado, espantado e chocado) e medo (desconfiado, medroso e apavorado). A inclusão de emoções derivadas, mas pertencentes ao mesmo grupo de emoções básicas, permitiu que o participante tivesse escolhas mais variadas para manifestar seus estados emocionais.

\section{FIGURA I}

\section{ILUSTRAÇÃO DAS EMOÇÕES BÂSICAS} APRESENTADAS AOS PARTICIPANTES
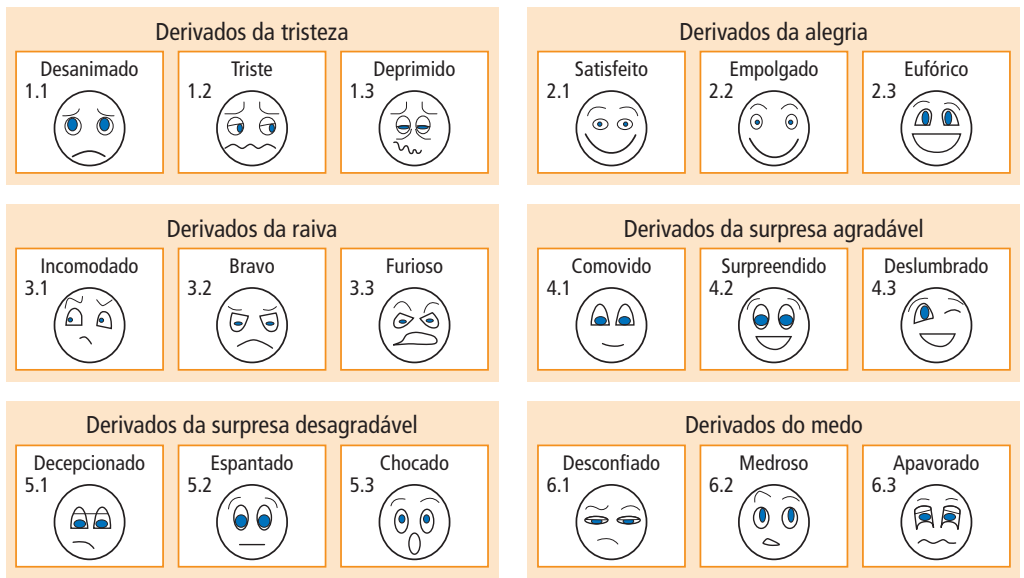

Fonte: Elaborada pelas autoras. 
Depois de escolher a emoção mais relevante para cada situação, o respondente, apenas para as sete situações negativas, era convidado a escolher a estratégia de regulação emocional que adotaria para resolver seu problema. Foram apresentadas nove estratégias de regulação emocional para lidar com a situação negativa, seis de estratégias profundas (a, b, c, d, e, f) e três de estratégias superficiais (g, h, i), assim especificadas: a) seleção da situação; b) modificação da situação, atenção posicionada, subdividida em: c) distração, d) concentração e e) ruminação; f) mudança cognitiva; g) controle de reações fisiológicas; h) regulação da expressão pela supressão; e i) compartilhamento social.

As estratégias de regulação emocional foram adaptadas dos trabalhos de Gross (I998, I999), como mostra o Quadro I.

\section{QUADRO I}

\section{ESTRATÉGIAS DE REGULAÇÃO EMOCIONAL}

\begin{tabular}{|c|c|c|}
\hline \multirow{6}{*}{$\begin{array}{l}\text { ESTRATÉGIAS } \\
\text { FOCADAS NOS } \\
\text { ANTECEDENTES } \\
\text { DA EMOÇÃOO }\end{array}$} & Seleção da situação & a) Evitaria essas situações no futuro. \\
\hline & Modificação da situação & $\begin{array}{l}\text { b) Preparar-me-ia emocionalmente para enfrentar } \\
\text { situações como essa no futuro. }\end{array}$ \\
\hline & \multirow{3}{*}{ Atenção posicionada } & $\begin{array}{l}\text { c) Não daria demasiada } \\
\text { importância a essa situação para } \\
\text { ela não me incomodar no futuro. }\end{array}$ \\
\hline & & concentração d) Refletiria sobre a situação. \\
\hline & & $\begin{array}{ll} & \text { e) Não conseguiria deixar de pensar } \\
\text { ruminação } & \text { no problema até perceber que } \\
\text { ele foi bem assimilado. }\end{array}$ \\
\hline & Mudança cognitiva & f) Buscaria avaliar o lado bom da situação. \\
\hline \multirow{3}{*}{$\begin{array}{l}\text { ESTRATÉGIAS } \\
\text { FOCADAS NOS } \\
\text { CONSEQUENTES } \\
\text { DA EMOÇÃO }\end{array}$} & $\begin{array}{l}\text { Controle de reações } \\
\text { fisiológicas }\end{array}$ & $\begin{array}{l}\text { g) Respiraria fundo ou usaria outros meios de } \\
\text { relaxar para diminuir o sentimento negativo. }\end{array}$ \\
\hline & $\begin{array}{l}\text { Regulação da expressão } \\
\text { pela supressão }\end{array}$ & $\begin{array}{l}\text { n) Evitaria demonstrar minha insatisfação e } \\
\text { desagrado com a situação. }\end{array}$ \\
\hline & $\begin{array}{l}\text { Compartilhamento } \\
\text { social }\end{array}$ & $\begin{array}{l}\text { i) Conversaria com outras pessoas sobre esses } \\
\text { sentimentos negativos. }\end{array}$ \\
\hline
\end{tabular}

Fonte: Elaborado pelas autoras.

Posteriormente, o questionário contemplou questões relativas aos dados pessoais e ocupacionais: sexo, ano de nascimento, estado civil, filhos, nível educacional, local de trabalho, quantidade de empregos, esfera pública, área (fim 
ou meio), tipo de regime de trabalho e grau de responsabilidade financeira pela manutenção da família.

\subsection{PROCEDiMENTOS DE COLETA, TRATAMENTO E ANÁlise DE DADOS}

A amostragem foi composta por critério de conveniência, conforme a disponibilidade e aceitação do indivíduo para participar da pesquisa. Em decorrência das inúmeras dificuldades de engajamento de participantes em pesquisas eletrônicas, optou-se pela coleta de dados presencial, que foi realizada no período de dezembro de 2010 a junho de 2011.

Para o tratamento dos dados coletados, utilizou-se o Statistical Package for Social Sciences (SPSS) apropriado para as ciências sociais. Foram usadas estatísticas descritivas de frequência e análise de variância.

Considerando que é mais frequente o uso de estratégias de regulação emocional em situações negativas (Gross, 2007), optou-se por centralizar a análise nas sete situações negativas. Foram, então, criados escores gerais de emoções negativas e positivas para simplificar a análise, visando identificar o seu predomínio em relação a cada uma das sete situações negativas. Preocupou-se, então, em apresentar uma análise descritiva das emoções negativas encontradas nas sete situações negativas e das estratégias de regulação profunda usadas pelos indivíduos da amostra. Posteriormente, procurou-se explicar os níveis de significância encontrados nas relações entre as variáveis sociodemográficas e o uso de estratégias de regulação profunda. Procurou-se testar, também, o efeito aditivo do sexo e da área (fim ou meio) na explicação da estratégia de regulação emocional profunda.

Para analisar a relação entre emoções, estratégias de regulação emocional e dados demográficos nos resultados obtidos na pesquisa, criou-se um escore de emoções positivas e negativas que se refere ao somatório dessas emoções para cada situação. Ou seja, para cada situação, foram somadas todas as emoções positivas e todas as emoções negativas, porém avaliaram-se apenas as estratégias de regulação emocional utilizadas para as emoções negativas.

\section{RESULTAdOS E DISCUSSÃO}

Para compreensão do leitor, serão descritas cada uma das sete situações negativas eliciadoras de emoções e as estratégias de regulação emocional usadas pelos servidores públicos. Cabe ressaltar que seis das sete situações negativas foram associadas a emoções negativas, porém, na quinta questão, ocorreu a predominância de emoções positivas. 
Na primeira situação, foi solicitado que o respondente imaginasse como se sentiria em função de uma reestruturação interna da organização, em que alguns setores fossem extintos, inclusive o dele. Do total da amostra dos servidores públicos, 93,3\% $(\mathrm{n}=374)$ sentiriam uma emoção negativa, e apenas 5,7\% $(\mathrm{n}=23)$ sentiriam emoções positivas. Das emoções negativas, a mais escolhida foi a raiva $5 \mathrm{I}, 5 \%(\mathrm{n}=\mathrm{I}$ ) $\mathrm{I})$.

Na segunda situação negativa, a organização havia decidido terceirizar alguns setores com o intuito de reduzir custos. Uma porcentagem elevada de servidores públicos, $86,5 \%(\mathrm{n}=347)$, escolheu emoções negativas, sendo a raiva a mais escolhida $36,6 \%(n=126)$.

A terceira situação se refere ao fato de a organização passar por uma crise administrativo-financeira e, em virtude disso, precisava cortar custos. Do total dos servidores da amostra, $86,5 \%(\mathrm{n}=347)$ disseram que sentiriam emoções negativas. A emoção de raiva foi igualmente a mais escolhida $28,8 \%(\mathrm{n}=\mathrm{IOO})$, seguida da tristeza 26,8 $(\mathrm{n}=93)$.

$\mathrm{Na}$ quarta situação, o respondente imaginava que havia recebido da organização uma avaliação negativa de seu desempenho. Dos participantes, 88,5\% $(n=355)$ escolheram emoções negativas, e destas, seguindo a prioridade das situações anteriores, a raiva foi novamente a emoção mais citada 53,1\% $(n=187)$.

A quinta situação descrita era que a organização havia implantando um novo sistema de avaliação de desempenho, com o intuito de identificar falhas no processo de trabalho. Nessa situação, contrariando a tendência das quatro situações anteriores, os servidores não optaram por emoções negativas. Somente $25,7 \%(\mathrm{n}=103)$ assinalaram emoções negativas, e a mais escolhida foi o medo $62,9 \%(\mathrm{n}=6 \mathrm{I})$. Essa foi a única situação negativa em que predominaram emoções positivas. Aqui talvez apareça a necessidade do servidor em receber feedback a respeito do seu trabalho. Um sistema de avaliação como esse permite que o indivíduo se situe com relação ao seu desempenho, de modo que perceba suas falhas e os aspectos positivos do seu trabalho. Essa necessidade de avaliação de desempenho talvez corrobore o predomínio do vínculo de comprometimento encontrado entre os servidores públicos. Indivíduos comprometidos e engajados talvez queiram reconhecimento pelo esforço do desempenho, e esse reconhecimento pode aparecer por meio de uma avaliação formal.

A sexta situação descrita fazia menção ao fato de a organização ter alterado o plano de saúde e passado a exigir a coparticipação dos funcionários no pagamento das despesas médicas para reduzir custos. Dos respondentes, 86,3\% $(\mathrm{n}=346)$ assinalaram emoções negativas, e, destas, a raiva foi a mais escolhida $38,4 \%$ $(\mathrm{n}=\mathrm{I} 32)$.

A sétima e última situação fazia referência a reuniões setoriais em que raramente as ideias dos funcionários e de colegas eram acatadas pela chefia. Do total 
dos servidores da amostra, 86\% ( $\mathrm{n}=345)$ escolheram emoções negativas, e, das emoções negativas, a maioria escolheu a surpresa desagradável 32,3\% ( $\mathrm{n}=$ III).

Em síntese, das sete situações negativas, a raiva apareceu como a mais citada em cinco delas. O medo e a surpresa desagradável foram citados em apenas uma situação, e a tristeza não apareceu como predominante em nenhuma, como mostra a Tabela I.

\section{TABELA I}

\section{FREQUENCIA E TIPOS DE EMOÇÃO ESCOLHIDOS NAS SETE SITUAÇÕES NEGATIVAS}

\begin{tabular}{|c|c|c|c|c|c|}
\hline \multicolumn{2}{|c|}{ SITUAÇÃO } & \multirow{2}{*}{ EMOÇÃO } & \multirow{2}{*}{$\mathrm{n}$} & \multirow{2}{*}{$\%$} & \multirow{2}{*}{$\begin{array}{c}\text { EMOÇÃO } \\
\text { PREDOMINANTE }\end{array}$} \\
\hline TEMA & EVENTO & & & & \\
\hline \multirow{2}{*}{$\begin{array}{l}\text { Reestruturação } \\
\text { interna }\end{array}$} & \multirow{2}{*}{ Extinção do setor } & Emoções positivas* & 23 & 6 & - \\
\hline & & Emoções negativas & 374 & 93 & Raiva \\
\hline \multirow{2}{*}{$\begin{array}{l}\text { Redução de } \\
\text { custos }\end{array}$} & \multirow{2}{*}{ Terceirização } & Emoções positivas & 50 & 12 & - \\
\hline & & Emoções negativas & 347 & 86 & Raiva \\
\hline \multirow{2}{*}{$\begin{array}{l}\text { Crise } \\
\text { administrativo- } \\
\text {-financeira }\end{array}$} & \multirow{2}{*}{ Redução de custos } & Emoções positivas & 50 & 12 & - \\
\hline & & Emoções negativas & 347 & 86 & Raiva \\
\hline \multirow{2}{*}{$\begin{array}{l}\text { Avaliação do } \\
\text { usuário }\end{array}$} & \multirow{2}{*}{$\begin{array}{l}\text { Desempenho } \\
\text { negativo }\end{array}$} & Emoções positivas & 41 & 10 & - \\
\hline & & Emoções negativas & 355 & 88 & Raiva \\
\hline \multirow{2}{*}{$\begin{array}{l}\text { Novo sistema } \\
\text { de avaliação de } \\
\text { desempenho }\end{array}$} & \multirow{2}{*}{$\begin{array}{l}\text { Falhas no processo } \\
\text { de trabalho }\end{array}$} & Emoções positivas & 294 & 73 & - \\
\hline & & Emoções negativas & 103 & 25 & Medo \\
\hline \multirow{2}{*}{$\begin{array}{l}\text { Alteração } \\
\text { no plano de } \\
\text { trabalho }\end{array}$} & \multirow{2}{*}{$\begin{array}{l}\text { Cobrança parcial } \\
\text { dos funcionários }\end{array}$} & Emoções positivas & 50 & 13 & - \\
\hline & & Emoções negativas & 346 & 86 & Raiva \\
\hline \multirow[b]{2}{*}{$\begin{array}{l}\text { Reuniões } \\
\text { setoriais }\end{array}$} & \multirow[b]{2}{*}{$\begin{array}{l}\text { Ideias não acatadas } \\
\text { pela chefia }\end{array}$} & Emoções positivas & 51 & 13 & - \\
\hline & & Emoções negativas & 345 & 86 & $\begin{array}{c}\text { Surpresa } \\
\text { desagradável }\end{array}$ \\
\hline
\end{tabular}

* Não foi incluída, na tabela, a emoção predominante de emoções positivas nas situações negativas, visto que o foco do estudo era a estratégia usada para lidar com as emoções negativas.

Fonte: Elaborada pelas autoras. 
A Tabela 2 apresenta as estratégias de regulação emocional usadas para manejar as sete situações apresentadas. Observa-se que, em seis das sete situações, os participantes indicaram usar estratégias de ação profunda para lidar com as situações negativas.

\section{TABELA 2}

TIPOS DE ESTRATÉGIA DE REGULAÇÃO EMOCIONAL USADOS PARA LIDAR COM AS SETE SITUAÇÕES

\begin{tabular}{|c|c|c|c|c|c|c|}
\hline \multicolumn{2}{|c|}{ SITUAÇÃO } & \multicolumn{4}{|c|}{$\begin{array}{c}\text { ESTRATÉGIA DE REGULAÇÃO } \\
\text { EMOCIONAL }\end{array}$} & \multirow{3}{*}{ PREDOMÍNIO } \\
\hline \multirow{2}{*}{ TEMA } & \multirow{2}{*}{ EVENTO } & \multicolumn{2}{|c|}{ PROFUNDA } & \multicolumn{2}{|c|}{ SUPERFICIAL } & \\
\hline & & $n$ & $\%$ & $n$ & $\%$ & \\
\hline Reestruturação interna & Extinção do setor & 253 & 72 & 98 & 28 & Profunda \\
\hline Redução de custos & Terceirização & 195 & 60 & 134 & 40 & Profunda \\
\hline $\begin{array}{l}\text { Crise administrativo- } \\
\text {-financeira }\end{array}$ & Redução de custos & 195 & 60 & 134 & 40 & Profunda \\
\hline Avaliação do usuário & $\begin{array}{l}\text { Desempenho } \\
\text { negativo }\end{array}$ & 225 & 68 & 105 & 32 & Profunda \\
\hline $\begin{array}{l}\text { Novo sistema de } \\
\text { avaliação de desempenho }\end{array}$ & $\begin{array}{l}\text { Falhas no processo } \\
\text { de trabalho }\end{array}$ & 65 & 69 & 29 & 31 & Profunda \\
\hline $\begin{array}{l}\text { Alteração no plano de } \\
\text { trabalho }\end{array}$ & $\begin{array}{l}\text { Cobrança parcial } \\
\text { dos funcionários }\end{array}$ & 177 & 55 & 148 & 45 & Profunda \\
\hline Reuniões setoriais & $\begin{array}{l}\text { Ideias não acatadas } \\
\text { pela chefia }\end{array}$ & 147 & 45 & 180 & 55 & Superficial \\
\hline
\end{tabular}

Fonte: Elaborada pelas autoras.

Para uma compreensão mais geral do peso das estratégias de regulação emocional de ação profunda, na escolha dos participantes, criou-se um escore do uso nas sete situações negativas que podia variar de zero a sete.

Com o intuito de estabelecer comparações entre categorias sociais e grupos da amostra de servidores públicos, e também analisar de modo mais detalhado a dimensão da variância explicada em relação ao uso da estratégia de ação profunda (valores de i a 7), considerada a mais adaptativa, procedeu-se a uma Anova (análise da variância) fatorial. Para a categoria social sexo (Tabela 3), encontrou-se uma diferença significativa, porém com baixa capacidade de explicação 
da variância $(2 \%)\left[\mathrm{F}_{(\mathrm{I}, 388)}=\mathrm{I0} .247, \mathrm{p}<.00 \mathrm{I}\right]$. Os homens $(\mathrm{M}=3.49$, dp $=\mathrm{I} .66)$ fazem mais uso da estratégia de ação profunda que as mulheres $(\mathrm{M}=2.97, \mathrm{dp}=$ I.54). Apesar de a diferença entre homens e mulheres não ter sido grande na amostra apresentada, as diferenças que apareceram podem ser amparadas pela literatura quando apresentam relações entre gênero e distinção de manifestações emocionais. A crença de que homens e mulheres regulam emoções de modo distinto é latente, porém a literatura ainda traz poucas explicações acerca dessas diferenças (McRae, Ochsner, Mauss, Gabrieli, \& Gross, 2008).

Referente a essa questão, existem muitos estereótipos relacionados ao uso e controle das emoções entre gêneros. Um deles, e talvez o mais comum, seja o de que as mulheres manifestem as emoções com mais facilidade do que os homens, porém uma afirmação desse tipo se torna muito vaga se analisada isoladamente. De acordo com Kostiuk e Fouts (2002), é possível perceber diferenças já nos processos de socialização de meninos e meninas. Para Sánchez-Núñez, Fernández-Berrocal, Montañés e Latorre (2008), nesse processo de socialização, os pais tendem a conversar mais sobre emoções com as filhas do que com os filhos, além do fato de se perceber uma tendência maior de as mães usarem mais termos afetivos nos diálogos do que os pais. As mães costumam encorajar mais demonstrações de afeto nas filhas do que nos filhos, o que tende a gerar, mais tarde, homens mais controlados nas manifestações emocionais do que mulheres. Talvez o uso de estratégias de regulação emocional profundas ajude a manter esse controle emocional por parte dos homens que irão desencadear as emoções, por meio de processos internos, fazendo com que reflitam mais sobre os fatos.

A partir dos processos de socialização, são desenvolvidas diferentes habilidades para lidar com emoções. McRae et al. (2008), todavia, apontam outra diferença ao afirmarem que os homens costumam reduzir quantitativamente suas emoções negativas, enquanto as mulheres tendem a reduzi-las qualitativamente, compensando emoções negativas com emoções positivas. Esse fato talvez ajude a explicar, em parte, as diferenças nas estratégias de regulação emocional usadas por homens e mulheres.

\section{TABELA 3}

DADOS SOCIODEMOGRÁFICOS E USO DAS ESTRATÉGIAS DE REGULAÇÃO EMOCIONAL

\begin{tabular}{lllll}
\hline VARIÁVEL & CATEGORIA & $M$ & DP & NIVEL DE SIGNIFICÂNCIA \\
\hline \multirow{2}{*}{ Sexo } & Feminino & 2.97 & 1.54 & \multirow{2}{*}{001} \\
\cline { 2 - 4 } & Masculino & 3.49 & 1.66 & \\
\hline
\end{tabular}




\section{TABELA 3 (Conclusão)}

DADOS SOCIODEMOGRÁFICOS E USO DAS ESTRATÉGIAS DE REGULAÇÃO EMOCIONAL

\begin{tabular}{|c|c|c|c|c|}
\hline VARIÁVEL & CATEGORIA & M & DP & NIVEL DE SIGNIFICÂNCIA \\
\hline \multirow{9}{*}{ Local de trabalho } & PMF & 3.02 & 1.43 & \multirow{9}{*}{.000} \\
\hline & Udesc & 3.17 & 1.66 & \\
\hline & Creci & 2.41 & 1.38 & \\
\hline & SPU-SC & 2.69 & 1.18 & \\
\hline & Secretaria da Educação & 2.95 & 1.64 & \\
\hline & MPU - SC & 2.15 & 1.34 & \\
\hline & Polícia Federal - SC & 3.35 & 1.70 & \\
\hline & Tribunais & 3.43 & 2.12 & \\
\hline & Comcap & 3.83 & 1.57 & \\
\hline \multirow{2}{*}{ Área } & Área-fim & 3.61 & 1.54 & \multirow{2}{*}{.000} \\
\hline & Área-meio & 2.91 & 1.62 & \\
\hline \multirow{3}{*}{ Nível } & Estratégico & 3.05 & 1.63 & \multirow{3}{*}{.001} \\
\hline & Tático & 2.94 & 1.65 & \\
\hline & Operacional & 3.56 & 1.53 & \\
\hline \multirow{3}{*}{ Regime de trabalho } & Estatutário & 3.97 & 1.66 & \multirow{3}{*}{.059} \\
\hline & Celetista & 3.52 & 1.68 & \\
\hline & Cargo comissionado & 2.84 & 1.34 & \\
\hline
\end{tabular}

Fonte: Elaborada pelas autoras.

Referente à instituição, os funcionários que fazem mais uso de estratégias profundas de regulação emocional pertencem à Comcap $(\mathrm{M}=3.83, \mathrm{dp}=\mathrm{I} .57)$, e os que fazem menor uso das estratégias profundas, ao MPU-SC ( $\mathrm{M}=2.15$, $\mathrm{dp}=\mathrm{I}$.34). A Comcap é responsável pela coleta, pelo transporte e tratamento de resíduos sólidos e pela limpeza dos logradouros e das vias públicas de Florianópolis. A amostra pesquisada foi constituída por garis que circulam a pé nas 
ruas e por coletores noturnos, caracterizados por funcionários que recolhem o lixo transitando em caminhões especiais para esse fim. O uso de estratégias profundas de regulação emocional pode ser explicado pelo perfil de trabalhadores que ocupam tais postos de trabalho e pelas características inerentes ao trabalho desses indivíduos. Conforme mencionado por Madruga (2002), o trabalho com coletores da Comcap se caracteriza pela exposição a riscos e por fortes exigências na execução das tarefas, além da insegurança, falta de perspectivas, não reconhecimento social e desgaste físico e emocional. Ou seja, tais funcionários estão um pouco mais expostos às pressões para a conformidade no ambiente de trabalho, o que torna necessário fazer uso de estratégias de regulação emocional profunda, visando mudar os sentimentos internos, estar em conformidade com as regras e conseguir levar adiante no exercício dessa atividade profissional.

O MPU-SC tem como objetivo zelar pela observância e pelo cumprimento da lei que abarca a defesa de interesses sociais, do patrimônio nacional, público, cultural e social, do meio ambiente e dos direitos e interesses da coletividade. O menor uso de estratégias profundas de regulação emocional pode decorrer do fato de o MPU oferecer melhores condições de trabalho e em razão do status social mais elevado em comparação com os funcionários da Comcap. A percepção de maior status social pode contribuir para que não haja uma pressão no que concerne a mudanças de sentimentos internos para estar em conformidade com as regras de expressão emocional exigidas pelo trabalho. Os funcionários sentem-se mais seguros para expressar suas emoções, ainda que sejam negativas e contrárias às regras ocupacionais e institucionais.

Em relação à área-fim (Figura 2), também foi encontrada diferença significativa $\left[\mathrm{F}_{(\mathrm{I}, 388)}=\mathrm{I} 8.0 \mathrm{II}, \mathrm{p}<.00 \mathrm{I}\right]$, mas com pouco poder de explicação da variância (4\%). As pessoas que estão na área-fim fazem mais uso de estratégias de ação profunda $(\mathrm{M}=3.6 \mathrm{I}, \mathrm{dp}=\mathrm{I} .54)$ do que aquelas que trabalham na área-meio $(\mathrm{M}=$ 2.9I, dp = I.62). Não foi encontrado efeito de interação entre as variáveis área e sexo $\left[\mathrm{F}_{(\mathrm{I}, 385)}=\mathrm{I} .4 \mathrm{I} 2, \mathrm{p}<.236\right]$, mas apenas de efeito aditivo, ou seja, homens fazem mais uso de estratégia profunda que mulheres, e as médias de ambos os sexos aumentam quando atuam em área-fim. As estratégias profundas são mais utilizadas nas áreas-fim, talvez por estarem mais alinhadas aos objetivos finais da organização pública e receberem feedbacks direto por sua maior proximidade com os cidadãos.

Encontraram-se diferenças no uso de estratégia de ação profunda entre locais distintos de atuação $\left[\mathrm{F}_{(8,375)}=4.084, \mathrm{p}<\right.$.00I], também com pequeno poder de explicação da variância. Dos nove locais de trabalhos em que atuam os servidores públicos da amostra, a Comcap apresentou as maiores médias de uso de estratégias de ação profunda ( $\mathrm{M}=3.83, \mathrm{dp}=\mathrm{I} .57)$, e o MPU-SC, a menor média $(\mathrm{M}=2 . \mathrm{I}$, dp = I.34) (Tabela 3). 


\section{FIGURA 2}

\section{EFEITO ADITIVO DA ÁREA DE ATUAÇÃO}

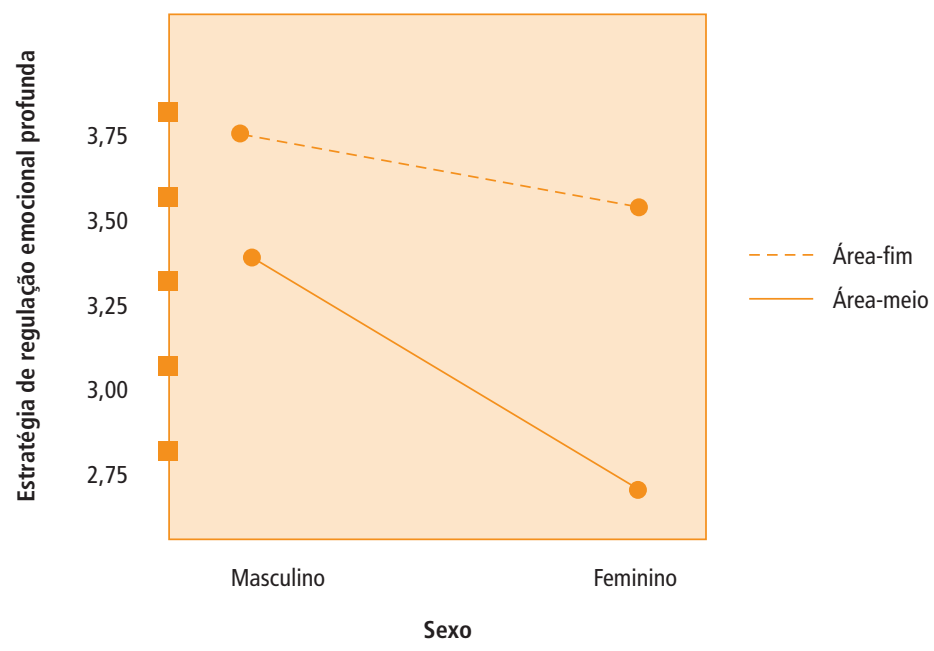

Fonte: Elaborada pelas autoras.

Em relação ao nível operacional, também foram encontradas diferenças significativas, com pequeno poder de variância explicada $\left[\mathrm{F}_{(2,387)}=6.86, \mathrm{p}<.00 \mathrm{I}\right]$, pois aqueles que trabalham no nível operacional fazem mais uso de estratégias de ação profunda que os demais níveis de atuação (Tabela 3). Indivíduos que fazem parte do nível operacional têm poucas oportunidades de mudar os processos de trabalho já estabelecidos pelos níveis tático e estratégico, e cabe aos indivíduos do nível operacional aceitar tais objetivos e se adaptar ao que foi preestabelecido. A flexibilidade de escolha nas decisões diante do contexto se torna menor. Diante de um contexto predefinido, cabe aos indivíduos que atuam no nível operacional se adaptar, a fim de manter o seu bem-estar. Esse contexto de adaptação talvez explique o uso de estratégias de regulação profunda com mais incidência entre eles. Estratégias profundas estão relacionadas ao esforço de manter o bem-estar. Elas são mais adaptativas a partir do momento em que o indivíduo reflete sobre o estímulo estressor e altera sua postura perante ele.

O fato de os estatutários também usarem mais estratégias profundas talvez possa ser explicado pela necessidade de se adaptarem em uma organização que, pela estabilidade, permanecerão por mais tempo. A concepção de permanência por um longo período, se comparada com indivíduos com cargos comissionados, que estão apenas de passagem pela organização, talvez leve os servidores sob o regime estatutário a perceber que precisam adequar suas emoções com o propósito de preservar o próprio bem-estar. 
$\mathrm{Na}$ amostra pesquisada, a raiva foi a emoção mais frequente. De acordo com Gibson, Schweitzer, Callister e Gray (2009), a raiva pode ser definida com uma emoção que varia de uma leve irritação a uma raiva intensa. Esse sentimento pode se manifestar por comportamentos verbais, não verbais e reações motoras. O resultado da frequência com que a raiva foi encontrada é corroborado pela pesquisa de Gibson et al. (2009) que, além de verificar a alta frequência dessa emoção, constatou que, se utilizada em pequena intensidade, pode ter consequências positivas no contexto organizacional. A ideia de a raiva provocar resultados positivos é defendida também por Gross (I999), a partir do momento em que é concebida como adaptativa e funcional no contexto em que está inserida. Porém, para Gibson et al. (2009), a raiva, quando sentida em grande intensidade, pode ser contraproducente, sobretudo quando o indivíduo perde o foco do evento que desencadeou a emoção.

É importante refletir sobre a manifestação de emoções negativas diante da busca pelo bem-estar na organização. Um dos principais ingredientes para uma vida saudável é a felicidade (Diener, Oishi, \& Lucas, 2003). Tanto a felicidade quanto a busca constante por satisfação fazem parte da construção do bem-estar. De acordo com Siqueira e Padovam (2008), a busca pelo bem-estar subjetivo inclui uma avaliação constante da qualidade das emoções. Nesse contexto, tanto a raiva, emoção predominante na amostra da pesquisa, quanto as demais emoções podem ter sido reguladas e controladas com o intuito de buscar resultados positivos.

A emoção menos frequente encontrada na amostra foi o medo, que está relacionado a possíveis riscos para o indivíduo. Talvez a pouca frequência do medo possa ser explicada pela ameaça de perder o emprego, que, na administração pública, por meio da estabilidade, se torna menor. A estabilidade talvez seja refletida em outros aspectos do ambiente organizacional, fazendo com que o indivíduo trabalhe menos ameaçado e, consequentemente, com menos medo, se comparado aos trabalhadores da iniciativa privada.

$\mathrm{Na}$ amostra pesquisada, para as emoções negativas, as estratégias mais frequentes de regulação emocional foram as de ação profunda. De acordo com Gross (20I3), as estratégias de regulação profunda são as mais eficazes na geração de mudanças cognitivas, a fim de preparar melhor o indivíduo para situações semelhantes no futuro. Segundo Schutte, Manes e Marouff (2009), as estratégias de regulação emocional profundas estão mais associadas ao bem-estar e a um maior nível de inteligência emocional para os indivíduos que a utilizam. 


\section{CONCLUSÕES}

Com base nas informações obtidas na amostra de servidores públicos, foi possível identificar e analisar as relações entre fenômenos com diferentes tradições de pesquisa na área de comportamento organizacional, o que, até o momento, não foi objeto de um estudo que os articulasse. Mais especificamente, foi possível atingir alguns resultados relevantes na análise das relações entre emoções e estratégias de regulação emocional por meio do manejamento de situações cotidianas de trabalho.

Quanto à manifestação de emoções negativas, predominou a raiva, e a emoção menos sentida foi o medo. Diante desse resultado, pode-se perceber um descontentamento dos servidores quanto ao trabalho que executam. A raiva é uma emoção que impulsiona o indivíduo para ações de mudança. A emoção negativa menos sentida pelos sujeitos da amostra foi o medo. Pode-se pensar que essa manifestação tenha relação com a estabilidade de emprego que pode levar a processos de acomodação e estagnação.

A emoção positiva mais sentida foi a alegria. E diante das situações negativas, as estratégias de regulação emocional profundas foram as mais usadas.

Quanto às emoções, não foram encontradas associações com as variáveis sociodemográficas. No que concerne às estratégias de regulação emocional, constataram-se relações quanto a sexo, área (meio ou fim), nível (federal, estadual e municipal) e regime de trabalho. As estratégias profundas foram mais frequentes em homens do que em mulheres, em trabalhadores da área-fim, em indivíduos que atuam no nível operacional e naqueles que trabalham sob o regime estatutário.

Finalmente, cabem algumas considerações sobre as contribuições e limitações para o estudo das emoções das estratégias de regulação emocional. Pesquisadores começam a se interessar pelos estudos comportamentais do servidor público. No Brasil, a literatura apresenta, ainda, certa escassez de pesquisas que ampliem a compreensão da dinâmica de vários fenômenos micro-organizacionais.

A necessidade de explorar mais elementos comportamentais no contexto do serviço público pôde ser percebida durante a coleta, em que muitos respondentes manifestaram interesse em participar da pesquisa como forma de expressar suas opiniões. Essas manifestações sugerem a necessidade de uma atuação mais ativa diante dos processos organizacionais no serviço público. Essa atitude, por parte dos trabalhadores, corrobora os resultados desta pesquisa que mostraram indivíduos mais comprometidos e envolvidos com a organização.

Com relação às emoções e estratégias de regulação emocional, além de uma pesquisa de natureza mais qualitativa, sugerem-se pesquisas de corte longitudinal 
em profundidade, com o propósito de avaliar as mudanças cognitivas e o desenvolvimento do indivíduo diante de fatos que desencadeiam emoções negativas.

Como nesta pesquisa foram exploradas as estratégias de regulação emocional diante de emoções negativas, devem-se pesquisar também estratégias diante de emoções positivas, a fim de fazer uma análise comparativa entre ambas.

Por fim, para se chegar ao estudo das peculiaridades das organizações públicas, devem ser realizadas pesquisas comparativas com o setor privado, com o intuito de perceber os aspectos organizacionais que os distingam e que sirvam de suporte para qualquer análise de cunho comportamental. Incluem-se aqui pesquisas acerca do controle emocional estabelecido pelos indivíduos, ressaltando a importância desses dois elementos para o bom desempenho e a adaptabilidade entre os indivíduos e a organização.

\section{EMOTIONAL EXPRESSION AND REGULATION IN WORKPLACE: A CASE STUDY WITH PUBLIC SERVANTS}

\section{ABSTRACT}

Emotions are characterized by a set of integrated responses that involve physiological and motor changes (that prepare the individual to act and feelings associated to internal experiences (allowing an situational evaluation). The emotional expressions are crucial to development and regulation of interpersonal relationships. Knowing how to deal with personal emotions and with others has become an important requirement in the relationships of the individual with the organization. Management of emotions has consequences in relationships among work pairs and in assistance to clients. Everyday work situations, organizational changes and clients and colleagues features involve emotions that need to be regulated. Emotional regulation can be defined as a controlled or automatic attempt in dealing with emotions showing how and why they will be felt and expressed. During the last years, public sector has been submitted to changes in its structure and dynamics that have required emotional management from public workers, demanding empirical studies aiming a better understanding of this reality. The quantitative study showed in this paper analyzed the relationships among emotions, emotional regulations strategies and sociodemographic variables of public workers in southern Brazil. Data were obtained using a questionnaire with examples of hypothetic everyday situations in the work. Participants were asked to choose emotional expressions associated to 
these situations and strategies of emotional regulation that could be used. The sample was formed by 400 . Results indicated that in everyday negative situations the prevalent emotions were associated to anger and the less prevalent were associated to fear. The emotional regulation strategies used to deal with situations were those of deep action. The results also showed the differences in emotional regulation regarding gender, activity level in the public organization and work regimen.

\section{KEYWORDS}

Emotion. Emotion regulation strategies. Public service. Organizational psychology. Organizational behavior.

\section{EXPRESIÓN Y REGULACIÓN EMOCIONAL EN EL CONTEXTO DEL TRABAJO: UN ESTUDIO CON SERVIDORES PÚBLICOS}

\section{RESUMEN}

Las emociones son caracterizadas por un conjunto integrado de respuestas que envuelven alteraciones fisiológicas y motoras (preparan el individuo para reaccionar) y sentimientos asociados a experiencias internas (proporcionan una evaluación de la situación). Las expresiones emocionales son cruciales al desarrollo y regulación de las relaciones interpersonales. Manejar las emociones personales además de las de otras personas se ha convertido en una importante exigencia en las relaciones del individuo con la organización. El manejo de las emociones repercute en las interacciones con los compañeros de trabajo y clientes. Las situaciones cotidianas del trabajo, los cambios organizacionales y las características de los clientes y compañeros de trabajo implican emociones que necesitan ser reguladas. La regulación puede ser definida como una tentativa controlada o automática de lidiar con las emociones indicando el cuando y la forma como son sentidas y expresadas. En los últimos años el sector público pasa por cambios en su estructura y dinámica que exigen el manejo emocional de los trabajadores, demandando, a la vez, estudios empíricos para comprender mejor esta realidad. El estudio cuantitativo descrito en este artículo analizó la relación entre emociones, estrategias de regulación emocional y variables sociodemográficas de servidores públicos empleados en organizaciones del sur de país. La recogida 
de datos fue realizada por medio de un cuestionario con ejemplos de situaciones hipotéticas del día a día en el trabajo para las cuales se pedía a los participantes que asociasen expresiones emocionales y estrategias de regulación a ser utilizadas en esas situaciones. La muestra fue de 400 trabajadores de diversas instituciones públicas. Los resultados indican que las emociones de rabia estaban asociadas a situaciones negativas del trabajo. El miedo estaba poco asociado a estas situaciones. Las estrategias de regulación emocional de acción profunda fueran las más asociadas a esas mismas situaciones. Los resultados muestran diferencias de regulación emocional asociadas al género, tipo de organización pública y jornada de trabajo.

\section{PALABRAS CLAVE}

Emociones. Estrategias de regulación emocional. Servicio público. Psicología organizacional. Comportamiento organizacional.

\section{REFERÊNCIAS}

Agüera, L. G. (2008). Além da inteligência emocional: as cinco dimensões da mente. São Paulo: Cengage Learning.

Augustine, A. A., \& Hemenover, S. H. (2008). On the relative effectiveness of affect regulation strategies: a meta-analysis. Cognition and Emotion, 23, II8I-I220.

Berkowitz, L. A. (2000). Anger. In T. Dalgleish \& M. J. Power. Handbook of cognition and emotion. London: John Wiley \& Sons.

Damasio, A. R. (1996). El error de Descartes (3a ed.). Santiago: Editorial Andres Bello.

Darwin, C. (2009) A expressão das emoções no homem e nos animais. São Paulo: Companhia das Letras. Diefendorff, J. M., Croyle, M. H., \& Gosserand, R. H. (2005). The dimensionality and antecedents of emotional labor strategies. Journal of Vocational Behavior, 66(issue 2), 339-357.

Diener, E., Oishi, S., \& Lucas, R. (2003). Personality, culture and subjective well-being: emotional and cognitive evaluations of life. Annual Review of Psychology, 54, 403-425.

Ekman, P. (1992). An argument for basic emotion. Cognition and Emotion, 6, I69-200.

Ekman, P. (I994). All emotions are basic. In P. Ekman \& R. J. Davidson (Orgs.). The nature of emotion: fundamental questions. New York: Oxford University Press.

Ekman, P. (2000). Basic emotions. In T. Dalgleish \& M. J. Power. Handbook of cognition and emotion. London: John Wiley \& Sons.

Esperidião-Antônio, V., Majeski-Colombo, M., Toledo-Monteverde, D., Moraes-Martins, G., Fernandes, J. J., Assis, M. B., \& Siqueira-Batista, R. (2008). Neurobiologia das emoções. Revista de Psiquiatria Clínica, 35, 55-65.

Freitas-Magalhães, A. Always emotional. (2010). In A. Freitas-Magalhães (Ed.). Emotional expression: the brain and the face. Oporto: University Fernando Pessoa Press. 
Gazzaniga, M. S., \& Heatherton, T. F. (2005). Ciência psicológica: mente, cérebro e comportamento. Porto Alegre: Artmed.

Gibson, D. E., Schweitzer, M. E., Callister, R. R., \& Gray, B. (2009). The influence of anger expressions on outcomes in organizations. Negotiation and Conflict Management Research, 2(3), 236-262. Gondim, S. M. G., \& Borges-Andrade, J. E. (2009). Regulação emocional no trabalho: um estudo de caso após desastre aéreo. Psicologia, Ciência e Profissão, 29(3), 512-533.

Gross, J. J. (1998). Antecedent- and response-focused emotion regulation: divergent consequences for experience, expression, and physiology. Journal of Personality and Social Psychology, 74, 224-237. Gross, J. J. (I999). Emotion regulation. Past, present, future. Cognition and Emotion, 13, 55I-573.

Gross, J. J. (2002, May). Emotion regulation: affective, cognitive, and social consequences. Psychophysiology, 39(3), 28I-29I.

Gross, J. J. (2007). Handbook of emotion regulation. London: The Guilford Press.

Gross, J. J. (2013). Handbook of emotion regulation. London: The Guilford Press.

Gross, J. J., \& John, O. (2003). Individual differences in two emotion regulation processes: implications for affect, relationships, and well-being. Journal of Personality and Social Psychology, 85, 348-362. Gross, J. J., \& Thompson, R. (2006). Emotion regulation: conceptual foundations. In J. J. Gross. Handbook of emotion regulation. New York: The Guilford Press.

Izard, C. E. (I99I). The psychology of emotions. New Youk: Plenum.

Izard, C. E. (20IO). The many meanings/aspects of emotion: definitions, functions, activation, and regulation. Emotion Review, 2(4), 363-370.

Izard, C. E., \& Ackerman, B. P. (2000). Motivational, organizational and regulatory functions of discrete emotions. In M. Lewis \& J. M. Haviland-Jones. Handbook of emotions. London: The Guilford Press.

Kostiuk, L., \& Fouts, G. (2002). understanding of emotions and emotion regulation in adolescent females with conduct problems: a qualitative analysis. The Qualitative Report, 7(I). Recuperado em Io junho, 20II, de http://www.nova.edu/ssss/QR/QR7-I/kostiuk.html.

Lazarus, R. S. (1982). Thoughts on the relations between emotion and cognition. American Psychologist, 37, IOI9-I024.

Lazarus, R. S., \& Folkman, S. (1984). Stress, appraisal, and coping. New York: Springer.

Madruga, R. B. (2002). Cargas de trabalho encontradas nos coletores de lixo domiciliar: um estudo de caso. Dissertação de mestrado, Universidade Federal de Santa Catarina, Florianópolis, SC, Brasil.

Mayer, J. D., Roberts, R. D., \& Barsade, S. G. (2006). Human abilities: emotional intelligence. The Annual Review of Psychology, 59, 507-36.

McRae, K., Ochsner, K. N., Mauss, I. B., Gabrieli, J. J. D., \& Gross, J. J. (2008). Gender differences in emotion regulation: an fMRI study of cognitive reappraisal. Group Processes \& Intergroup Relations, 11(2), I43-I62.

Miller, K., Considine, J., \& Garner, J. (2007). "Let me tell you about my job”: exploring the terrain of emotion in the workplace. Management Communication Quarterly, 20, 23I-260.

Plutchik, R. (1980). A general psychoevolutionary theory of emotion. In R. Plutchik \& H. Kellerman. Emotion: theory, research, and experience. New York: Academic Press.

Quoidbach, J., Berry, E. V., Hansenne, M., \& Mikolajczak, M. (20I0). Positive regulation and wellbeing: comparing the impact of eight savouring and dampening strategies. Personality and Individual Differences, 49(5), 368-373. 
Reeve, J. (2006). Motivação e emoção. Rio de Janeiro: LTC.

Sánchez-Núñez, M. T., Fernández-Berrocal, P., Montañés, J., \& Latorre, J. M. (2008). Does emotional intelligence depend and gender? The socialization of emotional competencies in men and women in its implications. Eletronic Journal of Research in Educational Psychology, 6(2), 455-474.

Schutte, N. S., Manes, R. R., \& Marouff, J. M. (2009). Antecedent-focused emotion regulation, response modulation and well-being. Current Psychology, 28, 2I-3I.

Sherer, K. (2000). Appraisal theory. In T. Dalgleish \& M. J. Power. Handbook of cognition and emotion. London: John Wiley \& Sons.

Siqueira, M. M., \& Padovam, V. A. R. (2008). Bases teóricas de bem-estar subjetivo, bem-estar psicológico e bem-estar no trabalho. Psicologia: Teoria e Pesquisa, 24, 20I-209.

Tomkins, S. S. (I984). Affect theory. In K. R. Scherer \& P. Ekamn. Approaches to emotion. New Jersey: Erlbaum.

Weiner, B. (I986). An attribuitional theory of motivation an emotion. New York: Springer, Verlag. 